\title{
Laboratório de Inovação Atenção Primária / 2017- Agência Nacional de Saúde - ANS/OPAS: as evidências foram comprovadas?
}

Tânia Kadima Magalhães Ferreira, André Luiz Fernandes Mascarenhas, Maria Amélia Matos Nicolau de Lima, Adriane de Oliveira Sales, Angela Leal Faoro

\section{Introdução:}

Pesquisa sobre operadoras aprovadas em Experiências de Atenção Primária (Saúde Suplementar), modelo para solucionar fragmentação do cuidado, mudanças demográficas e condições crônicas de saúde (desafios) pela ANS/OPAS (2017) mostrou divergências entre observação de critérios do edital: saúde, satisfação (beneficiários), e sustentabilidade (operadora), para reconhecer impacto das experiências com evidências comprovadas, e indicadores publicados pela ANS.

\section{Objetivos:}

Analisar experiências aprovadas (ANS/OPAS/OMS) com base no edital e em indicadores de qualidade das operadoras e financeiros publicados pela ANS.

\section{Metodologia:}

Pesquisa no site da ANS: aprovação no Laboratório de Inovação sobre Atenção Primária; pontuação das aprovadas no Programa de Qualificação das Operadoras: índice da dimensão da qualidade em atenção à saúde (IDQS), e sustentabilidade no mercado (IDSM), passando pela satisfação do beneficiário, conforme faixas: pior $0 \_0,2 \_0,4 \_0,6 \_0,8 \_1$ melhor; indicadores econômico-financeiros (Anuário/2017 ano base 2016).

\section{Resultados:}

Das 11 operadoras aprovadas, verificou-se que: 1) saúde: IDQS, 2 operadoras com pontuações baixas $(0,5368$ e 0,5984); 2) satisfação: IDSM, 8 operadoras nas piores faixas, $(0,3500)$; 3 ) sustentabilidade: sinistralidade (indicador operacional), 2 acima de 100\% (1,02 e 1,07); 5, com COMBA1 (despesas administrativas + despesas de comercialização + eventos indenizáveis líquidos / contraprestações efetivas) acima de 1,00 (1,01 a 1,07); liquidez corrente - LC (indicador financeiro), 1 sem LC (0,93); 9 com baixa LC $(1,0$ a 1,25); 1 com EBTIDA (representa quanto uma empresa gera de recursos através de suas atividades operacionais, sem contar impostos e outros efeitos financeiros ) negativo, e 1 com possível intervenção fiscal pela ANS.

\begin{tabular}{|c|c|c|c|c|c|c|}
\hline \multirow{2}{*}{ OPERADORAS } & \multicolumn{2}{|c|}{ INDICADORES EM ATENÇÃO A SAÚDE } & \multicolumn{4}{|c|}{ INDICADORES ECONÔMICOS - FNACEIROS } \\
\hline & IDQS & $\left({ }^{*}\right)$ IDSM & SINISTRALLDADE & COMBA (1) & LLQUIDEZ CORRENTE & MARGEM EBITDA \\
\hline AMIL & 1,00 & 0,35 & 0,84 & 1,00 & 1,05 & 0,00 \\
\hline CASSI & 0,78 & 0,35 & 1,02 & 1,11 & 1,09 & $-0,02$ \\
\hline FUNDAÇÃO SÃO FRANCISCO XAVIER & 0.87 & 0.65 & 0,83 & 0,89 & 3.42 & 0,20 \\
\hline SÃO FRANCISCO SISTEMAS E SAÚDE SOCIEDADE EMPRESÁRIA LTDA. & 1,00 & 0,35 & 0,76 & 0,93 & 1,21 & 0,08 \\
\hline SAUUDE BRB - CAIXA DE ASSISTENACIA & 0,80 & 1,00 & 1,07 & 1,27 & 8,58 & 0,30 \\
\hline UNIMED - BELO HORIZONTE COOPERATIA DE TRABALHO MÉDICO & 1,00 & 0,35 & 0,75 & 0,86 & 1,25 & 0,16 \\
\hline UNIMED DE GUARULLOS - COOPERATIVA DE TRABALHO MÉDICO & 0,59 & 0,35 & 0,90 & 1,03 & 0,93 & 0,02 \\
\hline UNMED GRANDE FLORIANÓPOLIS - COOPERATIVA DE TRABALHO MÉDICO & 0,53 & 0,35 & 0,84 & 0,97 & 1,04 & 0,06 \\
\hline UNIMED DE JABOTICABAL COOPERATIVA DE TRABALLO MÉDICO & 0,69 & 0,65 & 0,82 & 1,02 & 1,00 & 0,03 \\
\hline UNIMED JOÃO PESSOA COOPERATIVA DE TRABALHO MÉDICO & 086 & 0.35 & 082 & 093 & 106 & 0.3 \\
\hline $\begin{array}{l}\text { UNMED DE SANTA BARBARA DO OESTE E AMERICANA - COOPERATIVA DE } \\
\text { TRABALHO MEEDICO }\end{array}$ & 0,92 & 0,65 & 0,91 & 1,08 & 1,00 & 0,05 \\
\hline UNIMED DE VITÓRIA COOPERATIVA MÉDICO & 0,86 & 0,35 & 0,85 & 0,99 & 1,13 & 0,06 \\
\hline
\end{tabular}

(*) Avaliação referente a taxa de fiscalização (baseada no número de demandas NIP assistenciais e não assistenciais, classificadas como não resolvidas.

\section{Conclusão:}

Experiências em atenção primária/2017 mostrou divergência significativa entre resultados considerados exitosos e indicadores da ANS. Impacto das experiências na saúde e satisfação dos beneficiários, e sustentabilidade das operadoras não ficou totalmente evidenciado. Conclui-se que metodologia aplicada necessita ser revista para evitar comprometimento na credibilidade da Agência.

\section{Referências:}

site:www.ans.gov.br/planos-de-saude-e-operadoras/informacoes-e-avaliacoes-de-operadoras/qualificacao-ans; http://www.ans.gov.br/aans/noticias-ans/sobre-a-ans/4205-laboratorio-de-inovacao-seleciona-11-projetos-de-atencao-primaria; www.ans.gov.br/biblioteca/index.htm. 